\title{
A randomised, placebo controlled trial of inhaled salbutamol and beclomethasone for recurrent cough
}

\author{
Anne B Chang, Peter D Phelan, John B Carlin, Susan M Sawyer, Colin F Robertson
}

\begin{abstract}
Aims-To test the hypothesis that inhaled salbutamol or beclomethasone will reduce the frequency of cough in children with recurrent cough. A secondary aim was to determine if the presence of airway hyperresponsiveness (AHR) can predict the response.

Design-Randomised, double blind, placebo controlled trial.

Methods-During a coughing phase, 43 children (age 6-17 years) with recurrent cough were randomised to receive inhaled salbutamol or placebo (phase I) for 5-7 days and then beclomethasone or placebo (phase II) for 4-5 weeks, and in a subgroup of children for 8-9 weeks. The children used an ambulatory cough meter, kept cough diaries, and performed the capsaicin cough sensitivity, hypertonic saline bronchoprovocation, and skin prick tests. Results-Salbutamol or beclomethasone had no effect on cough frequency or score, irrespective of the presence of AHR.

Conclusions-Most children with recurrent cough without other evidence of airway obstruction, do not have asthma and neither inhaled salbutamol nor beclomethasone is beneficial.

(Arch Dis Child 1998;79:6-11)
\end{abstract}

Keywords: randomised control trial; cough; airway hyperreactivity; steroids; bronchodilator

Department of

Paediatrics, University of Melbourne

P D Phelan

Department of Clinical Epidemiology and Statistics, Royal Children's Hospital, Parkville, Melbourne, Victoria 3052, Australia

J B Carlin

Correspondence to: Dr A B Chang, Department of Respiratory Medicine, Mater Children's Hospital, South Brisbane, Queensland 4101, Australia.

email: achang@mater.org.au

Accepted 16 March 1998
(AHR) and atopy, among other factors. ${ }^{5}$ Currently there are proponents for ${ }^{67}$ and against $t^{14}$ the diagnosis of asthma in children with cough as the sole respiratory symptom (cough variant asthma). The proponents of the entity of cough variant asthma suggest a therapeutic trial of medications usually used to treat asthma including oral corticosteroids. ${ }^{6}$ Others have advocated the use of bronchoprovocative challenge to diagnose cough variant asthma. ${ }^{8}$ Previous studies that included asthma medications for cough variant asthma did not include placebo and used subjective methods for scoring cough, ${ }^{7-10}$ which is unreliable compared to objective measurements. ${ }^{11} 12$

In this randomised, double blind, placebo controlled trial, we tested the hypotheses that during a coughing period, inhaled salbutamol or inhaled steroids will reduce the frequency of cough (objectively measured) in children with recurrent cough. The objectives of the study were to examine the response of cough in children with recurrent cough to inhaled salbutamol and corticosteroid, and to relate the presence of AHR and increased cough receptor sensitivity (CRS) to the response of the children to these medications.

\section{Methods}

SUBJECTS

Children (6-17 years) with recurrent cough (two episodes of cough, each lasting two weeks in the past 12 months) were recruited from the outpatient department during a coughing episode, between July 1995 and March 1997. Exclusion criteria included the presence of a moist productive cough, bronchiectasis, whooping cough, immunodeficiency, clinical gastro-oesophageal reflux, a history of cardiac or neonatal pulmonary problems, abnormal cardiopulmonary physical examination including the presence of wheeze or abnormal spirometry (forced expiratory volume in one second $\left(\mathrm{FEV}_{1}\right)$ or forced vital capacity (FVC) $<85 \%$ predicted normal) or abnormal chest $x$ ray. Clinical gastro-oesophageal reflux was considered present if there was a positive response to any of the questions on recurrent symptoms of chest pain/heartburn, regurgitation, abdominal discomfort, bitter taste in the mouth, and difficulty swallowing. The parent(s) were interviewed and patients examined by a paediatrician (ABC). A history of wheeze, current wheeze (wheeze present in the past 12 months), exposure to cigarette smoke at home, 


\begin{tabular}{|c|c|c|c|c|c|c|}
\hline Day 1 & Day 2 & Days 5-7 & Phase II & Weeks 4-5 & & Weeks 8-9 \\
\hline \multirow{2}{*}{$\begin{array}{l}\text { Spirometry } \\
\text { Capsaicin CRST } \\
\text { HS challenge } \\
\text { Skin prick test } \\
\text { Cough meter } \\
\text { Cough score chart }\end{array}$} & $\begin{array}{l}\text { Randomised } \\
\text { to salbutamol }\end{array}$ & \multirow{2}{*}{\begin{tabular}{|l} 
Spirometry \\
Capsaicin CRST \\
Cough meter \\
Cough score chart
\end{tabular}} & $\begin{array}{l}\text { Re-randomised to } \\
\text { beclomethasone }\end{array}$ & $\begin{array}{l}\text { Spirometry } \\
\text { Capsaicin CRST } \\
\text { Cough meter }\end{array}$ & \multirow{2}{*}{\multicolumn{2}{|c|}{$\Rightarrow \begin{array}{l}\text { Spirometry } \\
\text { Capsaicin CRST } \\
\text { Cough meter } \\
\text { Cough score chart }\end{array}$}} \\
\hline & or placebo & & or placebo & Cough score chart & & \\
\hline
\end{tabular}

Figure 1 Study protocol. In phase I, subjects were randomised to receive inhaled salbutamol or placebo; in phase II, subjects received inhaled beclomethasone or placebo. In a subgroup of subjects, phase II was prolonged so that subjects received 8-9 weeks of inhaled medications. CRST, cough receptor sensitivity test; HS hypertonic saline.

and family history (immediate family) of asthma and atopy (eczema, hay fever) were obtained. Pertussis serology and a chest $x$ ray were performed if the child had not had an $x$ ray with the onset of the current cough. Written consent was obtained from parent(s) and the study was approved by the hospital's ethics committee for human research.

STUDY PROTOCOL

On day 1 the children performed (in order) baseline spirometry, the capsaicin CRS test, repeat spirometry, hypertonic saline challenge, and skin prick test (fig 1). An ambulatory cough meter was used for 24 hours. The children were then randomised (double blind, in blocks of six) to receive two puffs twice a day of either inhaled salbutamol $(100 \mu \mathrm{g}$ per puff of Ventolin; Allen and Hanburys, Australia) or placebo, delivered via a large volume spacer (Volumatic; Allen and Hanburys) for 5-7 days (phase I). At the end of phase I, the subjects were retested while still on the trial drugs. On the following day, they were re-randomised (phase II) to receive two puffs twice a day of either inhaled beclomethasone $(100 \mu \mathrm{g}$ per puff, Becotide; Allen and Hanburys) or placebo. The subjects were retested 4-5 weeks later, and a subgroup of subjects were tested 8-9 weeks later. Compliance was measured by weighing the canisters before and after the trial. Compliance was considered acceptable if there was a $>70 \%$ reduction in the weight of the canisters.

Spirometry (Jaeger, Germany that meets American Thoracic Society criteria) was performed and the best of three attempts was recorded. Skin prick test was performed once using lancets (ALK lancets; Allergologisk, Denmark) and six allergens (Hollister Stier, Elkhart, USA): cat pelt, dog dander, house dust mix, rye grass, grass mix, mould mix, as well as positive (histamine $10 \mathrm{mg} / \mathrm{ml}$ ) and negative (diluent) controls. Wheal size was measured as the mean of the two diameters at right angles. Atopy was defined as the presence of a wheal of $3 \mathrm{~mm}$ more than the negative control to one or more allergen. ${ }^{13}$

Capsaicin CRS test

We have previously described a method of performing the capsaicin CRS test in children, which has good repeatability. ${ }^{14}$ Briefly, capsaicin (Sigma-Aldrich, Australia) diluted in $20 \%$ alcohol, was delivered through a nebuliser controlled by a dosimeter (MB3, MEFAR, Italy) in a configuration that allowed regulation of the inspiratory flow. The dosimeter was set at 0.7 seconds inhalation time, and normal saline and diluent controls were given before doubling concentrations of capsaicin $(1.23-1250 \mu \mathrm{mol})$ were inhaled. The number of coughs in the subsequent 30 seconds were counted by an independent observer. CRS measures were the lowest concentration of capsaicin required to stimulate $\geqslant 2$ coughs (Cth) and $\geqslant 5$ coughs (C5). In our laboratory, the repeatability of this test as measured by the $95 \%$ range for intraobserver change is 1.08 and 1.03 doubling dose for Cth and C5, respectively (0.33 and 0.31 in log values, respectively). ${ }^{14} \mathrm{CRS}$ is considered to be heightened or increased when Cth and C5 values are lower.

\section{Hypertonic saline challenge}

Hypertonic saline $(4.5 \%)$ challenge was performed as described by Riedler and colleagues. ${ }^{15}$ Trial medications were withheld before testing-phase I drugs for 6 hours, phase II drugs on the morning of testing. Briefly, using an ultrasonic nebuliser (Timeter MP500, Lancaster, USA) the dose of hypertonic saline was increased successively by doubling the inhalation time $(0.5,1,2,4,8$ minutes). $\mathrm{FEV}_{1}$ was measured 60 seconds after each inhalation time and the test ceased when the $\mathrm{FEV}_{1}$ had fallen by $\geqslant 15 \%$ or when a cumulative inhalation time of 15.5 minutes had been achieved. PD15 was defined as the amount of hypertonic saline (provocation dose) causing a fall in $\mathrm{FEV}_{1}$ of $\geqslant 15 \%$ from baseline. It was obtained by linear interpolation of individual dose-response curves constructed by plotting the percentage fall in $\mathrm{FEV}_{1}$ from the baseline on a linear scale against the cumulative dose delivered (in millilitres) on a $\log _{10}$ scale. The presence of AHR (AHR positive) was defined as a fall in $\mathrm{FEV}_{1}$ of $\geqslant 15 \%$ from the baseline at any time during the hypertonic saline challenge. We have previously shown that capsaicin inhalation before hypertonic saline challenge does not alter airway responsiveness of children with or without asthma. ${ }^{16}$

\section{Cough meter}

We have previously described and validated a new ambulatory cough meter that is based on a modified Holter monitor. ${ }^{17}$ The cough meter continuously records simultaneous electromyogram (EMG) and acoustic signals for 24 hours.

\section{Cough score charts}

The parent(s) and child were given a colour coded chart and were asked to rate separately the severity of the child's cough using a visual 
Table 1 Characteristics of the subjects randomised to the two treatment arms

\begin{tabular}{|c|c|c|c|c|}
\hline & \multicolumn{2}{|l|}{ Phase I } & \multicolumn{2}{|l|}{ Phase II } \\
\hline & $\begin{array}{l}\text { Placebo } \\
(n=22)\end{array}$ & $\begin{array}{l}\text { Salbutamol } \\
(n=21)\end{array}$ & $\begin{array}{l}\text { Placebo } \\
(n=21)\end{array}$ & $\begin{array}{l}\text { Beclo- } \\
\text { methasone } \\
(n=22)\end{array}$ \\
\hline Median age (range), years & $8.5(6-15)$ & $10.2(6-17)$ & $9.2(6-15)$ & $8.5(6-17)$ \\
\hline $\operatorname{Sex}(M: F)$ & $11: 11$ & $8: 13$ & $7: 14$ & $12: 10$ \\
\hline Period of current cough, weeks ${ }^{\star}$ & $8(8.3)$ & $8(10.5)$ & $12(7.5)$ & $7(9)$ \\
\hline History of recurrent cough, months ${ }^{\star}$ & $24(27)$ & $24(26)$ & $24(31)$ & $24(36)$ \\
\hline Smoke exposure (n) & 5 & 8 & 8 & 5 \\
\hline History of past wheeze (n) & 11 & 13 & 12 & 12 \\
\hline Eczema (n) & 4 & 4 & 3 & 5 \\
\hline Atopy $(\mathrm{n})$ & 10 & 15 & 11 & 14 \\
\hline Airway hyperresponsiveness (n) & 8 & 6 & 4 & 10 \\
\hline Family history of asthma (n) & 14 & 13 & 14 & 13 \\
\hline Family history of atopy (n) & 17 & 16 & 16 & 17 \\
\hline $\mathrm{FEV}_{1} \%$ predicted (SE) & $98(3)$ & $109(4)$ & $101(4)$ & $104(3)$ \\
\hline FVC \%predicted (SE) & $101(2)$ & $109(3)$ & $104(3)$ & $105(2)$ \\
\hline
\end{tabular}

There was no significant difference between the two groups for any variable in either phase.

*Median (interquartile range).

Table 2 Baseline data and the effect of phase I medications on outcome variables at day $5-7$

\begin{tabular}{|c|c|c|c|}
\hline Outcome variable & Placebo & Salbutamol & $p$ value ${ }^{\star}$ \\
\hline \multicolumn{4}{|c|}{ Cough frequency (number in 24 hours) } \\
\hline Baseline, geometric mean (SD) & $85(3.5)$ & $53(2.6)$ & \\
\hline$\%$ change, mean $(95 \% \mathrm{CI})$ & $-34(-60,8)$ & $-45(-74,163)$ & 0.24 \\
\hline \multicolumn{4}{|l|}{ Symptom score (parent completed) } \\
\hline Baseline, median (IQR) & $4.5(2.8)$ & $3.1(3)$ & \\
\hline Change, mean $(95 \% \mathrm{CI})$ & $-0.5(-1.6,0.6)$ & $-0.9(-2,0.3)$ & 0.12 \\
\hline \multicolumn{4}{|l|}{ Symptom score (child completed) } \\
\hline Baseline, median (IQR) & $3.9(3.8)$ & $3(2.5)$ & \\
\hline Change, mean $(95 \% \mathrm{CI})$ & $-1.2(-2.3,0.02)$ & $-0.9(-2,0.1)$ & 0.31 \\
\hline \multicolumn{4}{|l|}{$\log _{10}$ Cth $(\mu \mathrm{mol})$} \\
\hline Baseline, median (IQR) & $0.84(1.05)$ & $0.99(0.6)$ & \\
\hline Change, mean $(95 \% \mathrm{CI})$ & $0.07(-0.22,0.36)$ & $0.14(-0.11,0.39)$ & 0.45 \\
\hline \multicolumn{4}{|l|}{$\log _{10} \mathrm{C} 5(\mu \mathrm{mol})$} \\
\hline Baseline, median (IQR) & $1.29(1.02)$ & $1.44(0.6)$ & \\
\hline Change, mean $(95 \% \mathrm{CI})$ & $0.16(-0.17,0.49)$ & $0.2(-0.1,0.49)$ & 0.34 \\
\hline
\end{tabular}

${ }^{\star}$ Comparison of change between the groups (linear regression adjusted for baseline).

$\mathrm{IQR}$, interquartile range.

Table 3 Baseline data and the effect of phase II medications on outcome variables at week 4-5

\begin{tabular}{|c|c|c|c|}
\hline Outcome variable & Placebo & Beclomethasone & $p$ value * \\
\hline \multicolumn{4}{|c|}{ Cough frequency (number in 24 hours) } \\
\hline Baseline, geometric mean (SD) & $27(4.2)$ & $63(2.3)$ & \\
\hline$\%$ change, $(95 \% \mathrm{CI})$ & $-45(-74,18)$ & $-72(-88,-33)$ & 0.82 \\
\hline \multicolumn{4}{|l|}{ Symptom score (parent completed) } \\
\hline Baseline, median (IQR) & $3.4(3.7)$ & $3.5(4.3)$ & \\
\hline Change, mean $(95 \% \mathrm{CI})$ & $-1.5(-2.4,-0.5)$ & $-0.9(-1.7,-0.1)$ & 0.45 \\
\hline \multicolumn{4}{|l|}{ Symptom score (child completed) } \\
\hline Baseline, median (IQR) & $2.7(4.1)$ & $3(4.2)$ & \\
\hline Change, mean ( $95 \%$ CI) & $-1.5(-2.5,-0.6)$ & $-0.9(-1.7,-0.1)$ & 0.28 \\
\hline \multicolumn{4}{|l|}{$\log _{10}$ Cth $(\mu \mathrm{mol})$} \\
\hline Baseline, median (IQR) & $0.99(1.1)$ & $0.99(1.2)$ & \\
\hline Change, mean $(95 \% \mathrm{CI})$ & $0.06(-0.17,0.3)$ & $-0.17(-0.44,0.1)$ & 0.08 \\
\hline \multicolumn{4}{|l|}{$\log _{10} \mathrm{C} 5(\mu \mathrm{mol})$} \\
\hline Baseline, median (IQR) & $1.29(1.2)$ & $1.59(0.75)$ & \\
\hline Change, mean $(95 \% \mathrm{CI})$ & $0.08(-0.2,0.36)$ & $-0.01(-0.3,0.28)$ & 0.69 \\
\hline
\end{tabular}

${ }^{\star}$ Comparison of change between the groups (linear regression adjusted for baseline).

$\mathrm{IQR}$, interquartile range.
STATISTICAL ANALYSIS

Chi-squared test with Yates's correction was used to compare categorical values between the groups. Cough frequency, Cth, and C5 values were $\log _{10}$ transformed. Paired Wilcoxon test was used to analyse outcome measures in the same individuals. Shapiro-Wilks and Lilliefors tests were used to examine for normality of distribution. Comparison of group means were adjusted for baseline values using linear regression. The required sample size $(n=21$ on each arm) was calculated using the data from the first 10 subjects to detect a reduction of $70 \%$ in the mean number of coughs per 24 hours. At its conclusion, the power of the study at a significance level of 0.05 was $80 \%$. Subjects who did not complete the study were analysed as intention to treat-that is, subjects were analysed in the group to which they were randomly assigned. ${ }^{18}$

\section{Results}

Fifty five children were considered for the study, and 43 children were randomised (phase I: salbutamol $n=21$, placebo $n=22$; phase II: beclomethasone $\mathrm{n}=22$, placebo $\mathrm{n}=21$ ). Twelve children were excluded: pertussis (3), productive cough (3), inability to perform hypertonic saline challenge (2), psychogenic cough (2), current wheeze on examination (1), immunosuppressive medications (1). Thirty eight children completed the study. Five children (four from the active treatment group and one from the placebo group for both phases) did not complete the study: personal reasons (3), use of salbutamol in addition to trial medications (1, from placebo group), refusal to take the trial medications (1, from active treatment group). In three children, the cough meter analysis was unsatisfactory: microphone dislodged (1), cough meter removed because of intolerable itch (2). Two children (both 6 years old) could not complete the score charts. Subject characteristics were similar in both treatments in both phases (table 1).

PHASE I

Cough frequency, subjective scores, and other outcome variables did not alter significantly in either treatment arm. Nor was there a significant difference between the groups (table 2). Twenty eight of the 38 children who completed the study (13 in treatment arm, 15 in placebo arm) were apparently compliant with medication use.

PHASE II

Cough frequency before re-randomisation was higher in the beclomethasone treated group compared to the placebo group (difference of $58 \%, 95 \%$ confidence interval (CI) $80 \%, 8 \%$ ), (table 3). Symptom score improved significantly in both treatment arms. The beclomethasone treated group improved in cough frequency but the difference in improvement between the treatment arms was not significant when the values were corrected for baseline difference. At 8-9 weeks of treatment, the cough frequency was not significantly reduced compared to the values at 4-5 weeks (difference $-8(95 \%$ CI $-29,13)$ coughs in 24 hours When data from the cough meter unavailable, a $70 \%$ reduction in the subjective cough score was defined as treatment success. 

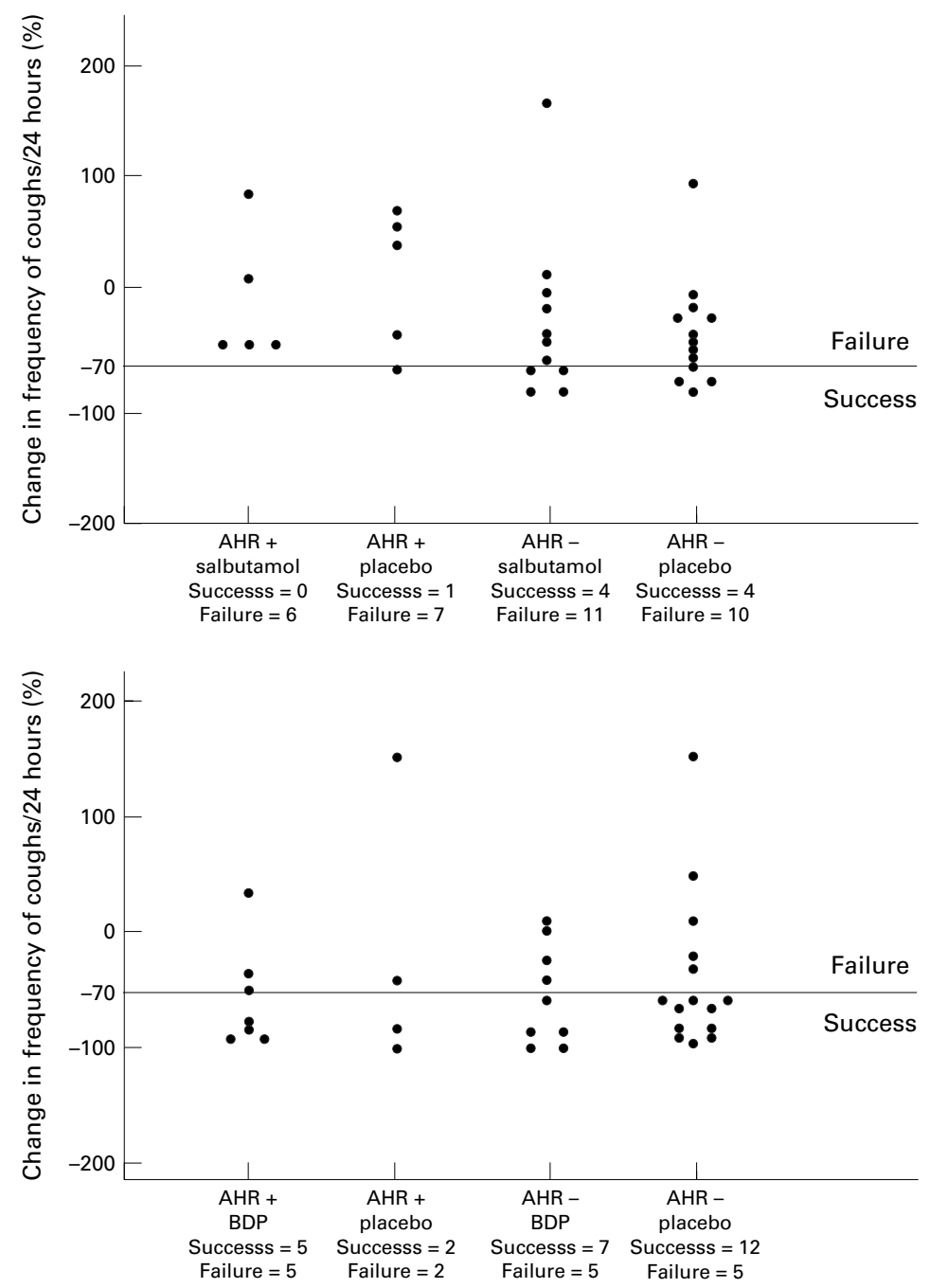

Figure 2 Graph showing percentage change in cough frequency in the subjects with $(A H R+)$ and without (AHR-) airway hyperresponsiveness in $(A)$ phase I and $(B)$ phase II. Summary of outcome success and failure at the bottom of both graphs includes subjects who were withdrawn $(n=5)$ and those where the cough meter analyses were inadequate $(n=3)$. BDP, beclomethasone.

for placebo group $v-32(-62,3)$ for beclomethasone group). There was no significant difference in the change in CRS in either group (table 3). Twenty three of the 38 children who completed the study (10 in treatment arm, 13 in placebo arm) were compliant with medication use in phase II.

AIRWAY HYPERRESPONSIVENESS

When grouped by AHR, the CRS on day 1 of AHR negative subjects ( $\mathrm{n}=29$, log Cth: 0.68 (95\% CI 0.51, 0.85); log C5: 1.14 (95\% CI $0.9,1.38)$ ) was significantly higher than the CRS in the AHR positive subjects $(\mathrm{n}=14, \log$ Cth: 1.38 (95\%CI 1.09, 1.67); log C5: 1.81 $(95 \%$ CI $1.34,2.28))$. There was no significant difference in the change in cough frequency between the AHR positive and AHR negative groups (fig 2).

SUCCESS AND FAILURES

Figure 2 summarises treatment success and failure; there was no significant difference between treatment success and failures in either phase I or phase II.

\section{Discussion}

In this first placebo controlled, randomised trial that objectively monitored the cough response to inhaled salbutamol and steroids, we found that neither medication was better than placebo in reducing either objective or subjective measures of cough. We have also demonstrated that during a coughing period in these children, those without AHR have heightened sensitivity to coughing compared with those with AHR. A minority of children had AHR, and the presence of AHR was not related to the response to these inhaled medications.

This study supports growing epidemiological evidence ${ }^{45}$ that cough alone is a poor marker for asthma. McFadden and colleagues were the first to describe cough as a presenting symptom of asthma in adults. ${ }^{2}$ All subjects in this study had exertional dyspnoea and abnormal baseline expiratory flow volume loops consistent with moderate airways obstruction. ${ }^{2}$ Subsequent studies of cough variant asthma included adults and children without any abnormality of their baseline pulmonary function. $^{791019}$ Many of these studies ${ }^{7} 101920$ used asthma medications for adults and children with cough variant asthma but had no placebo arm, and results were based on subjective reporting of cough, which is known to be unreliable. ${ }^{11}$ Although earlier studies on cough variant asthma used theophylline and/or terbutaline, ${ }^{7}{ }^{1020}$ later studies included corticosteroids, both inhaled and oral. ${ }^{89}$ Cheriyan and colleagues' retrospective study reported that eight of their 10 adult patients were free from cough while on either oral or inhaled corticosteroids after three months. ${ }^{9}$ In the earlier adult $^{19}$ and paediatric ${ }^{7}$ studies, the subjects' cough responded to oral theophylline within $2-5$ days, ${ }^{79}$ in contrast to the prolonged course of steroids required by other studies. ${ }^{9}$ Our study is not comparable to other studies that included children with abnormal baseline lung function ${ }^{10} 20$ or chest physical examination. ${ }^{10}$ The subjects in our study had normal physical examination and spirometry. In one study, ${ }^{10}$ a third of the 32 children had abnormal physical examination of the chest and 12 of the 20 children who were able to perform pulmonary function tests had abnormalities in the expiratory flow loop. Similarly, in another study, ${ }^{20}$ six of the eight children who were able to perform pulmonary function tests had $\mathrm{FEV}_{1}$ predicted values of $<85 \%$.

Our study questions the existence of cough variant asthma (cough as the only respiratory symptom without any evidence of airway obstruction). It also raises the appropriateness of the common practice of using either $\beta_{2}$ agonists or inhaled steroids in the treatment of children with cough without any other evidence of airway obstruction. In our clinical practice, we have seen a number of children prescribed inappropriately high doses of inhaled or oral steroids or both for many weeks. Identifying children who are unlikely to benefit from medications used for asthma could not only potentially prevent the diagnostic labelling of asthma in a large group of children but also 
save these children from the use of unnecessary medications and their associated side effects, as well as save their parents from any unnecessary expense. We were, however, unable to relate the presence of AHR to the child's response to asthma medications. Nevertheless, while a short therapeutic trial of medications used to treat asthma may be justified in some children with recurrent cough, the results from this study suggest that a trial of prolonged or high dose corticosteroids is not indicated.

There are several possible explanations as to why the AHR positive children in this study responded no differently from AHR negative children to the inhaled medications. First, AHR in children is variable and, among other factors, is dependent on age, the presence of a viral infection, and airway calibre. Second, although AHR is usually present in patients with asthma, the presence of AHR does not equate with asthma, especially in children. ${ }^{21}$ Pin and colleagues showed that the cells of induced sputum from asymptomatic children with AHR (to methacholine) differed from children with asthma, but resembled normal subjects. ${ }^{22}$ In epidemiological studies, the presence of AHR cannot reliably define adults ${ }^{23}$ and children ${ }^{24}$ with and without asthma. Studies that suggest that AHR is widely present in all asthmatics and can reliably separate asthmatic from non-asthmatic subjects have been from highly selective groups, often hospital based subjects. ${ }^{25}$ In children, the use of AHR alone to diagnose asthma is indeed contentious. ${ }^{2124}$

Although cough is often used as a marker of asthma instability, ${ }^{26}$ the severity of cough has been shown to be unrelated to the airway calibre as measured by $\mathrm{FEV}_{1}$, peak expiratory flow or its variability. ${ }^{11}$ In the laboratory, medications (cromolyn, atropine) that inhibit the bronchoconstriction that occurs with bronchoprovocative challenges do not alter the cough response. ${ }^{27} 28$ Conversely, other medications (lignocaine, codeine) that inhibit the induced cough have no effect on bronchoconstriction. ${ }^{27}{ }^{29}$ In human airways, the pathways for cough and bronchoconstriction are distinctly different. ${ }^{28-30}$ While the trigger for cough and airway narrowing may be the same, the symptom of cough may persist despite adequate treatment of bronchoconstriction. It is, therefore, not surprising that the AHR positive children in our study responded to salbutamol and placebo in a similar manner to the AHR negative children.

We suspect that most of the children in this study with heightened CRS had postviral cough. In an earlier study, we showed that the heightened CRS in children with recurrent cough returns to control levels when they are cough free. ${ }^{31}$ In adults, increased CRS has been associated with upper respiratory infection and the use of ACE inhibitors, ${ }^{32}$ but not in children with clinical asthma ${ }^{30}$ or adults with productive cough. ${ }^{33}$

The number of subjects in our study was small, but large enough to achieve a power of $80 \%$ based on an expected difference of $70 \%$ in the frequency of cough. A larger number of subjects would be necessary if a smaller expected difference was used. However, as previous studies of cough variant asthma achieved a complete resolution of cough, ${ }^{719}$ we believe that a $70 \%$ reduction was reasonable. Nevertheless, a type II error is possible and a larger study to confirm or dispute our findings is encouraged.

A potential criticism of our study is that silent gastro-oesophageal reflux and sinusitis were not thoroughly investigated. In children, these diagnoses as a cause of cough, rather than an association, are controversial. The exclusion of sinusitis is extremely difficult. In a prospective study, $50 \%$ of the 137 children younger than 13 years $^{34}$ had computed tomography sinus scans consistent with sinusitis but all were asymptomatic. In adults with gastrooesophageal reflux (but no respiratory symptoms) reflux was found to be a cofactor and not the cause of cough. ${ }^{35}$ As most of the children in our study became cough free (all but two) at follow up without specific treatment for gastrooesophageal reflux or sinusitis, we believe that these diagnoses are not important in this study.

It could also be argued the infrequent use of salbutamol in this trial affected the outcome measures. Salbutamol was used twice a day rather than four times a day, with the aim of improving compliance. Moreover, regular use of $\beta$ agonists (three to four times a day) may worsen asthma symptoms, increase the risk of severe asthma or cause enhanced AHR. ${ }^{36}$ As compliance and treatment success were similar in both treatment arms, improved compliance and a larger daily dose of salbutamol are unlikely to alter our final results. In addition, there is no gold standard on acceptable compliance and devices that record the use of the medication cannot confirm if the medication was actually consumed. ${ }^{37}$

The promotion of the diagnosis of asthma based on the symptom of cough alone has led to the overuse of steroids in children with recurrent cough. ${ }^{1}$ Our findings of a lack of response to inhaled medications used routinely for asthma, irrespective of the presence of AHR, are supported by epidemiological data. $^{38}{ }^{39}$ Clifford and colleagues found no association between cough and AHR nor atopy after controlling for wheeze, and they suggested that, in the absence of wheeze, the significance of cough and dyspnoea for the diagnosis of asthma in epidemiological studies should be questioned. ${ }^{38}$ In a recent prospective study, the presence of AHR to cold air at age 6 years was not predictive of the development of asthma at age 11 years, when the presence of atopy and wheeze were controlled for. ${ }^{39}$ We chose to include children with a history of wheeze in our study as this symptom can be under ${ }^{1}$ or overevaluated. In an earlier study, we found that a history of current wheeze could not differentiate children with from those without AHR to hypertonic saline challenge. ${ }^{31} \mathrm{We}$ also included children who were diagnosed as asthmatic as local experience suggests that this label is used very loosely.

While cough is associated with asthma, ${ }^{2}$ when no other evidence of airway obstruction 
is present we have shown that, irrespective of the presence of AHR, inhaled salbutamol and beclomethasone were no different from placebo in reducing the frequency of cough measured objectively or scored subjectively. We conclude that in children with recurrent cough without other evidence of airway obstruction, neither inhaled salbutamol nor beclomethasone is beneficial. The common problem of cough in childhood and its relation with airway obstruction deserves further investigation.

Dr AB Chang is supported by the National Health and Medical Research Council (Australia). Medications were supplied by Allen and Hanburys, Victoria, Australia. We are indebted to the paediatricians, Drs Olinsky, McNamara, Allen, Gold, and James paediatricians, Drs Olinsky, McNamara, Allen, Gold, and James
for referring their patients for the study. We also thank the for referring their patients for the study. We also thank the
department of cardiology for the loan of their Holter monitor and reader.

1 McKenzie S. Clinical features and their assessment. In Silverman M, ed. Childhood asthma and other wheezing Silverman M, ed. Childhood asthma and other wheez
disorders. London: Chapman \& Hall, 1995:175-200.

$2 \mathrm{McF}$ adden ER. Exertional dyspnea and cough as precludes McFadden ER. Exertional dyspnea and cough as precludes
to attacks of bronchial asthma. N Engl $\mathcal{F}$ Med 1975;292: $555-9$.

3 Kelly YJ, Brabin BJ, Milligan PJM, Reid JA, Heaf D, Pearson MG. Clinical significance of cough and wheeze in the diagnosis of asthma. Arch Dis Child 1996;75:489-93.

4 Ninan TK, Macdonald L, Russell G. Persistent nocturna cough in childhood: a population based study. Arch Di Child 1995;73:403-7.

5 Wright AL, Holberg CJ, Morgan WJ, Taussig LM, Halonen M, Martinez FD. Recurrent cough in childhood and its relation to asthma. Am f Respir Crit Care Med 1996;153: 1259-65.

6 Doan T, Patterson R, Greenberger PA. Cough variant asthma: usefulness of a diagnostic-therapeutic trial with prednisolone. Ann Allergy 1992;69:505-9.

7 Cloutier MM, Loughlin GM. Chronic cough in children: a manifestation of airway hyperreactivity. Pediatrics $1981 ; 67$ : manifesta.

8 Irwin RS, Curley FJ, French CL. Chronic cough. The spectrum and frequency of causes, key components of the diagnostic evaluation, and outcome of specific therapy. Am Rev Respir Dis 1990;141:640-7.

9 Cheriyan S, Greenberger PA, Patterson R. Outcome of cough variant asthma treated with inhaled steroids. Ann Allergy 1994;73:478-80.

10 Hannaway PJ, Hopper GDK. Cough variant asthma in children. FAMA 1982;247:206-8.

11 Hsu JY, Stone RA, Logan-Sinclair RB, Worsdell M, Busst $\mathrm{CM}$, Chung KF. Coughing frequency in patients with persistent cough assessment using a 24 hour ambulatory recorder. Eur Respir f 1994; 7:1246-53.

12 Archer LN, Simpson H. Night cough counts and diary card scores in asthma. Arch Dis Child 1985;60:473-4.

13 Dreborg S. Bronchial hyper-reactivity and skin sensitivity. Clin Exp Allergy 1991;21:529.

14 Chang AB, Phelan PD, Roberts RG, Robertson CF. Capsaicin cough receptor sensitivity test in children. Eur Respir $\mathcal{F}$ 1996:9:2220-3.

15 Riedler J, Reade T, Dalton M, Holst D, Robertson C. Hypertonic saline challenge in an epidemiologic survey of asthma in children. Am J Respir Crit Care Med 1994;150 1632-9.

16 Chang AB, Phelan PD, Holst D, Robertson CF. The effect of capsaicin on airway responsiveness to hypertonic saline in asthmatic and non asthmatic children. Pediatr Pulmonol 1997:23: 412-16.
17 Chang AB, Newman RG, Phelan PD, Robertson CF. A new use for an old Holter monitor: an ambulatory cough meter. Eur Respir F 1997 10:1637-9.

18 Armitage P, Berry G. Statistical methods in medical research. 3rd ed. Oxford: Blackwell Scientific Publications, 1994: 193-4.

19 Carrao WM, Braman SS, Irwin RS. Chronic cough as the sole presenting manifestation of bronchial asthma. $N$ Engl f Med 1979;300:633-7.

20 König P. Hidden asthma in children. Am f Dis Child 1981; 135:1053-5.

21 Wilson N, Silverman M. Bronchial responsiveness and its measurement. In: Silverman M, ed. Childhood asthma and measurement. In: Silverman M, ed. Childhood asthma and
other wheezing disorders. London: Chapman \& Hall, other wheezin
1995:142-75.

22 Pin I, Radford S, Kolendowics R, et al. Airway inflammation in symptomatic and asymptomatic children with methacholine hyperresponsiveness. Eur Respir f 1993;6:1249-56.

23 Enarson DA, Vedal S, Schulzer M, Dybuncio A, ChanYeung M. Asthma, asthma-like symptoms, chronic bronchitis, and the degree of bronchial hypereresponsiveness in epidemiological surveys. Am Rev Respir Dis 1987;136:61367.

24 Pattemore PK, Asher MI, Harrison AC, Mitchell EA, Rea $\mathrm{HH}$, Stewart AW. The interrelationship among bronchial hyperreponsiveness, the diagnosis of asthma, and asthma hyperreponsiveness, the diagnosis of asthma, and
symptoms. Am Rev Respir Dis 1990;142:549-54.

25 Cockroft DW, Killian DN, Mellon JAA, Hargreave FE. Bronchial reactivity to inhaled histamine: a method and clinical survey. Clin Allergy 1977;7:235-43.

26 Isles A, Robertson CF. Treatment of asthma in children and adolescents: the need for a different approach. Med $\mathcal{F}$ Aust 1993;158:761-3.

27 Hansson L, Choudry NB, Fuller RW, Pride NB. Effect of nedocromil sodium on the airway response to inhaled capsaicin in normal subjects. Thorax 1988;43:935-6.

28 Sheppard D, Rizk NW, Boushey HA, Bethel RA. Mechanism of cough and bronchoconstriction induced by
distilled water aerosol. Am Rev Respir Dis 1983;127:691-4.

29 Fuller RW, Karlsson JA, Choudry NB, Pride NB. Effect of inhaled and systemic opiates on responses to inhaled
capsaicin in humans. F Appl Physiol 1988;65:1125-30.

30 Shimuzu T, Mochizuki H, Tokuyama K, Morikawa A. Relationship between acid-induced cough response and airway responsiveness and obstruction in children with asthma. Thorax 1996;51:284-7.

31 Chang AB, Phelan PD, Sawyer SM, Robertson CF. Cough receptor sensitivity and airway hyper-responsiveness in children with non-specific recurrent cough. Am 7 Respir Crit Care Med 1997;155:1935-9.

32 O'Connell F, Thomas VE, Pride NB, Fuller RW. Capsaicin cough sensitivity decreases with successful treatment of chronic cough. Am $\mathcal{f}$ Respir Crit Care Med 1994;150:37480 .

33 Choudry NB, Fuller RW. Sensitivity of the cough reflex in patients with chronic cough. Eur Respir f 1992;5:298-300.

34 Diament MJ, Senac MO, Gilsanz V, Baker S, Gillespie T, Larsson S. Prevalence of incidental paranasal sinuses opacification in pediatric patients: a CT study. $f$ Comput Assist Tomogr 1987;11:426-31.

35 Ferrari M, Oliveri M, Sembenini C, et al. Tussive effect of capsaicin in patients with gastroesophageal reflux without cough. Am f Respir Crit Care Med 1995;151:557-61.

36 Busse WW, Maisiak R, Young KR Jr. Treatment regimen and side effects of treatment measures. Am $\mathcal{F}$ Respir Crit Care Med 1994;149:S44-50.

37 Rand CS, Wise RA. Measuring adherence to asthma medication regimens. Am F Respir Crit Care Med 1994;149: S69-76.

38 Clifford RD, Howell JB, Radford M, Holgate ST. Associations between respiratory symptoms, bronchial response to methacholine, and atopy in two age groups of schoolchildren. Arch Dis Child 1989;64:1133-9.

39 Lombardi E, Morgan WJ, Wright AL, Stein RT, Holberg CJ, Martinez FD. Cold air challenge at age 6 and subsequent incidence of asthma. Am f Respir Crit Care Med 1997;156:1863-9. 